\title{
Timing of thoracic irradiation in limited stage small-cell lung cancer: is it still a star on the rise?
}

\author{
Farkhad Manapov, MD, Maximilian Niyazi, MD, Minglun Li, MD \\ Department of Radiation Oncology, University of Munich, Germany
}

Early cisplatin-based concurrent chemoradiotherapy (CRT) is a mainstay treatment in limited stage small-cell lung cancer (LS SCLC; the Union for International Cancer Control stage IIII). This is based on the several randomized trials and metaanalyses. Most considerable of them are the National Cancer Institute of Canada (NCIC), Intergroup-0096, and the Japan Clinical Oncology Group (JCOG)-9104 trials [1-3]. These studies included pre-chemotherapy extent of the tumor in radiation portals and demonstrated 5-year survival rates over 20\%. Importantly, starting point and application of thoracic irradiation (TRT) in these trials was different. In NCIC study mild hypofractionated TRT was applied with the second cycle whereas in the INT-0096 and JCOG-9104 (concurrent arm) trials accelerated hyperfractionated radiotherapy was started with the first cycle of chemotherapy. In all these trials TRT began within 30 days after initiation of chemotherapy, treatment time of TRT was less than 30 days and dose delivery of chemotherapy and TRT was more than 80\%. Another substantial aspect was that deferred application of TRT in the late arms of NCIC and JCOG-9104 trials resulted in the increase of $\mathrm{CRT}$ duration as a whole treatment. A retrospective study has reported that in LS SCLC duration of CRT, itself, can also affect overall survival.

Recently published randomized phase III trial of Sun et al. [4] demonstrated that outcome achieved with TRT starting with the third cycle of chemotherapy is non-inferior to results when radiotherapy was administered from the first day of systemic treatment. Median survival, remission rates and estimated 5-year survival rates were equal in early and late arms and comparable with best historical results. Although total radiation dose was lower than actual standard, dosedelivery of chemotherapy and TRT was high. In the late TRT arm initially involved lymph nodes were considered in the target definition even a significant response occurred after the second chemotherapy cycle.

How can we declare the results of this study? Most relevant finding of Sun et al. [4] is, probably, the fact that in both arms complete responders to CRT demonstrated significant better outcome compared to partial and non-responders. Complete response remains to be highly significant variable correlating with overall survival on the multivariate analysis. This strong correlation is very important and was not reported in the earlier randomized trials. Solely, study of Jeremic et al. [5] found higher complete remission rate in the early TRT arm accompanied with better long-term results, but remission grade of the tumor, itself, was not analysed as a prognostic factor.

There is a growing body of evidence to keep response of the tumor in course of CRT under control. Small studies have already demonstrated that rapid achievement of complete remission in LS SCLC can be a significant prognostic factor.

Received 20 July 2013, Accepted 22 July 2013.

Correspondence: Farkhad Manapov, MD, Department of Radiation Oncology, University of Munich, Marchioninistraße 15, 81377 Munich, Germany. Tel: +49-89-70953770, Fax: +49-89-70956770, E-mail: farkhad.manapov@med.uni-muenchen.de

(c) This is an Open Access article distributed under the terms of the Creative Commons Attribution Non-Commercial License (http://creativecommons.org/ licenses/by-nc/3.0/) which permits unrestricted non-commercial use, distribution, and reproduction in any medium, provided the original work is properly cited.

www.e-roj.org 


\section{References}

1. Murray N, Coy $P$, Pater $J$, et al. Importance of timing for thoracic irradiation in the combined modality treatment of limited-stage small-cell lung cancer. The National Cancer Institute of Canada Clinical Trials Group. J Clin Oncol 1993;11:336-44.

2. Turrisi AT, Kim K, Blum $R$, et al. Twice-daily compared with once-daily thoracic radiotherapy in limited small-cell lung cancer treated concurrently with cisplatin and etoposide. N Engl J Med 1999;340:265-71.

3. Takada M, Fukuoka M, Kawahara M, et al. Phase III study of concurrent versus sequential thoracic radiotherapy in combination with cisplatin and etoposide for limited-stage small-cell lung cancer: results of the Japan Clinical Oncology Group study 9104. J Clin Oncol 2002;20:3054-60.

4. Sun JM, Ahn YC, Choi EK, et al. Phase III trial of concurrent thoracic radiotherapy with either first- or third-cycle chemotherapy for limited-disease small-cell lung cancer. Ann Oncol 2013;24:2088-92.

5. Jeremic B, Shibamoto Y, Acimovic L, Milisavljevic S. Initial versus delayed accelerated hyperfractionated radiation therapy and concurrent chemotherapy in limited small-cell lung cancer: a randomized study. J Clin Oncol 1997;15:893900. 